\title{
Letter to the Chief Editor: Outcome of thoracolumbar burst fractures treated with indirect reduction and fixation without fusion. Huilin Yang, Jin-hui Shi, Molly Ebraheim, Xiaochen Liu, Joseph Konrad, Ibrahim Husain, Tian-si Tang, Jiayong Liu Eur Spine J. Published online 8 August 2010
}

\author{
François Lucas $\cdot$ Evelyne Emery
}

Received: 10 November 2010/Accepted: 27 December 2010/Published online: 18 January 2011

(C) Springer-Verlag 2011

We read with great interest the article written by Liu et al. This retrospective study included patients with type A or C according AO classification non-osteoporosis thoracolumbar fractures. They were treated with posterior fixation without fusion after indirect reduction. Almost all patients had instrumentation removal at 9-12 months post-operative. The authors report good long-term outcome for the great majority of included patients.

However, the authors report adjacent disc injury and disc degeneration after implants removal without clinical deterioration.

According to Roaf [5], the intervertebral disc is always stronger than the vertebral end plate and excessive compression force creates an end-plate fracture. Several animal experimental studies have shown that end-plate fracture can occur when there is pressurization of the nucleus [1]. These studies allow us to hypothesize that human vertebral end-plate fractures are due to excessive nucleus pressurization when brutal compressive loading is transmitted. In this context, disc-end plate interface restoration seems to be one of the main objectives in compressive fractures (type A of Magerl classification) treatment.

Disc height loss leading to kyphosis is the main complication of vertebral fractures. MRI analysis of the disc signal have showed no significant signal intensity modification, and more particularly, no degeneration process. According to Oner [2], the disc changes are the consequences of adaptation to the morphological changes of the end plate with settling of the end-plate defect. Indirect reduction does not allow restoration of the mechanical properties of the end plate-disc interface. Moreover, pedicle screw instrumentation does not prevent recurrent kyphosis, particularly with short arthrodesis (one level above, one level below) [3].

In our point of view, disc height loss is not a disc degenerative process but an adaptation to new mechanical conditions. Vertebroplasty [4] allows to improve the vertebral body mechanical quality, particularly at the disc-end plate interface. Therefore, this technique seems to prevent disc height loss and recurrent kyphosis.

\section{References}

1. Brown SHM, Gregory DE, McGill SM (2008) Vertebral end-plate fractures as a result of high rate pressure loading in the nucleus of the young adult porcine spine. J Biomech 41:122-127

2. Oner FC, van der Rijt RR, Ramos LMP, Dhert WJ, Verbout AJ (1998) Changes in the disc space after fractures of the thoracolumbar spine. J Bone Jt Surg Br 80-B:833-839

3. McLain RF, Sparling E, Benson DR (1993) Early failure of shortsegment pedicle instrumentation for thoracolumbar fractures. A preliminary report. J Bone Jt Surg Am 75:162-167

4. Oner FC, Dhert WJA, Verlaan J (2005) Less invasive anterior column reconstruction in thoracolumbar fractures. Injury 36(Suppl 2):B82-B89

5. Roaf R (1960) A study of the mechanics of spinal injuries. J Bone Jt Surg Br 42-B:810-823 